\title{
Latest Development and Application of High Strength and Heavy Gauge Pipeline Steel in China
}

\author{
Zhang Yongqing ${ }^{1}$, Guo Aimin ${ }^{1}$, Shang Chengjia ${ }^{2}$, Liu Qingyou ${ }^{3}$, J. Malcolm Gray ${ }^{4}$ and Frank Barbaro ${ }^{5}$ \\ 1. CITIC Metal Co., Ltd, Capital Mansion, Chaoyang district, Beijing, China \\ 2. University of Science and Technology Beijing, Beijing 100083, China \\ 3. Central Iron \& Steel Research Institute, Beijing 100081, China \\ 4. Microalloyed Steel Institute 5100 Westheimer, Suite 540, Houston, TX 77056, USA \\ 5. CBMM Technology Suisse, 14, Rue du Rhone, Geneve 1204, Switzerland
}

\begin{abstract}
Over the past twenty years, significant advances have been made in the field of microalloying and associated applications, among which one of the most successful application cases is HTP practice for heavy gauge, high strength pipeline steels. Combined the strengthening effects of TMCP and retardation effects of austenite recrystallization with increasing Nb in austenite region, HTP conception with low carbon and high niobium alloy design has been successfully applied to develop X80 coil with a thickness of 18.4 mm used for China's Second West-East pipeline. During this process, big efforts were made to further develop and enrich the application of microalloying technology, and at the same time the strengthening effects of $\mathrm{Nb}$ have been completely unfolded and fully utilized with improved metallurgical quality and quantitative analysis of microstructure. In this paper, the existing status and strengthening effect of $\mathrm{Nb}$ during reheating, rolling, and cooling have been analyzed and characterized based on mass production samples and laboratory analysis. As confirmed, grain refinement remains the most basic strengthening measure to reduce the microstructure gradient along the thickness, which in turn enlarges the processing window to improve upon low temperature toughness, and finally make it possible to develop heavy gauge, high strength pipeline steels with more challenging fracture toughness requirements. As stated by a good saying that practice makes perfect. Based on application practice and theoretical analysis, HTP has been extended to develop heavy gauge and high strength pipeline steels with increasing requirements, including X80 SSAW pipe with a thickness of $22.0 \mathrm{~mm}$ and above, X80 LSAW pipe combining heavy gauge and large diameter, heavy gauge X80 LSAW pipe with low temperature requirements, as well as X90 steels. In this paper, alloy design, production processing, as well as mechanical properties and microstructure used for these products would be illustrated.
\end{abstract}

Key words: HTP, high strength pipeline steel, low carbon bainitic microstructure.

\section{Introduction}

As described by Greek mythology, Prometheus' theft of fire from Olympus for the benefit of humanity, and then human civilization started to develop. Anyway, energy has become an indispensable part for modern civilization and daily life, even the induced factor of international conflict. Coincidentally, niobium also got its name from Greek mythology: Niobe, daughter of Tantalus. As said by Mr. Mirror Cohen in his paper of Microalloying '75: "For the foreseeable future, the technology of microalloyed

Corresponding author: Zhang Yonqing, senior engineer, research fields: microalloying technology and pipeline steel. steels will be greatly influenced by mankind's ever-growing demands for energy. In fact, there is an inseparable reciprocity between energy and materials in general, with each mirroring the other". Among all application fields of microalloyed steels, large diameter pipeline steels was firstly studied and spread to other structural sector. What is more, niobium played a significant role for its pronounced effect on retardation recrystallization and grain refinement coupled with thermo-mechanical processing (controlled rolling and controlled cooling) and currently used HTP (high temperature processing). Just as concluded by Mr. Kozasu, a worldwide well-known 
expert, niobium is footstone of chemical design and metallurgy in high strength pipeline steel.

Here I am honored to present the metallurgical design of X80 strip used for the China's Second West-East pipeline based on production practice, and at the same time to validate the expectation and conclusion of early predecessors. One of the most important features for the Second's West-East pipeline is the Class one area with 0.72 design parameter employed $\Phi 1,219 \times 18.4 \mathrm{~mm}^{2}$ spiral welded pipe, rather than conventional longitudinal welded pipe made from X80 plate. Table 1 shows the basic requirements of mechanical properties, of which $30^{\circ}$ tensile direction is the most weak. With the technical support from CBMM's technical experts, HTP technology with low carbon and high niobium alloy design had been introduced, and laid the foundation for early production practice, but it is equally important that low coiling temperature up to $300{ }^{\circ} \mathrm{C}$ played a significant role for successful development.

\section{Metallurgical Design and Production Processing}

It is well known that a low carbon bainitic microstructure (acicular ferrite) offers the optimum combination of strength and toughness, especially when formed from nonrecrystallised austenite, namely TMCP (typical thermo-mechanical processing). Compared with traditional ferrite plus pearlite, this new kind of bainitic microstructure is composed of a mixture of bainitic ferrite with high dislocation density and carbon enriched martensite regions, mainly existing as discrete islands, named MA islands. In order to achieve low carbon bainitic microstructure (acicular ferrite), grain refinement and transformation strengthening are the two pronounced characteristics besides traditional solution strengthening and precipitation strengthening. Fig. 1 gives the typical three controlled rolling processes, namely conventional controlled rolling (TMCP), RCR (recrystallization controlled rolling) and HTP (hot temperature processing). With powerful rolling mills put into operation, RCR ultimately came to an end because of strength limitation of ferrite-pearlite structure, whereas HTP ushered in its time for X80 pipeline steels with demanding toughness requirements, in particular in China.

Considering the tensile direction of $30^{\circ}$ to the rolling, the actual equivalent strength level is close to X90 or $\mathrm{X} 100$ of steel plate. So the metallurgical design of X100 firstly proposed by Europipe was referred for D design process of X80 strip, as shown from Fig. 2. Based on HTP practice, a steel with maximum $0.06 \% \mathrm{C}$, $1.85 \% \mathrm{Mn}, 0.25 \% \mathrm{Mo}, 0.10 \% \mathrm{Nb}, 0.25 \% \mathrm{Cu}$ and $0.25 \% \mathrm{Ni}$ was preferred in the beginning stage. As presented by early trial results, the yield strength levels remained unstable. For this case, coiling temperature was firstly lowered to $300{ }^{\circ} \mathrm{C}$ based on CCT diagram of recommended chemical compositions, as shown from Fig. 3. In the past, the designed coiling temperature is higher than $500{ }^{\circ} \mathrm{C}$ according to equipment ability. As presented by recent HIPERC project undertaken by European steel mills and research institutes, the set cooling stop temperature for X80 hot-coiled plate are higher than $500{ }^{\circ} \mathrm{C}$. So, it is first time for China's steel mills to carry out coiling temperature up to $300{ }^{\circ} \mathrm{C}$, which later regarded as the key reason for the successful development. In addition, Mr. Volker Schwinn and co-author gave their analysis results on relationship between mechanical properties and

Table 1 Requirements of mechanical properties of X80 hot rolled coil.

\begin{tabular}{lll}
\hline Properties & Specified value & Test direction \\
\hline YS (Rt0.5) & $555-690 \mathrm{MPa}$ & \\
TS (Rm) & $625-825 \mathrm{MPa}$ & \\
Y/T (Rt0.5/Rm) & $0.94(\max )$ & $30^{\circ}$ to the rolling direction \\
Charpy Impact Energy at $-20^{\circ} \mathrm{C}$ & $180 / 240 \mathrm{~J}$ (single/average) & \\
Shear area of DWTT at $-15^{\circ} \mathrm{C}$ & $70 / 85 \%$ (single/average) \\
\hline
\end{tabular}




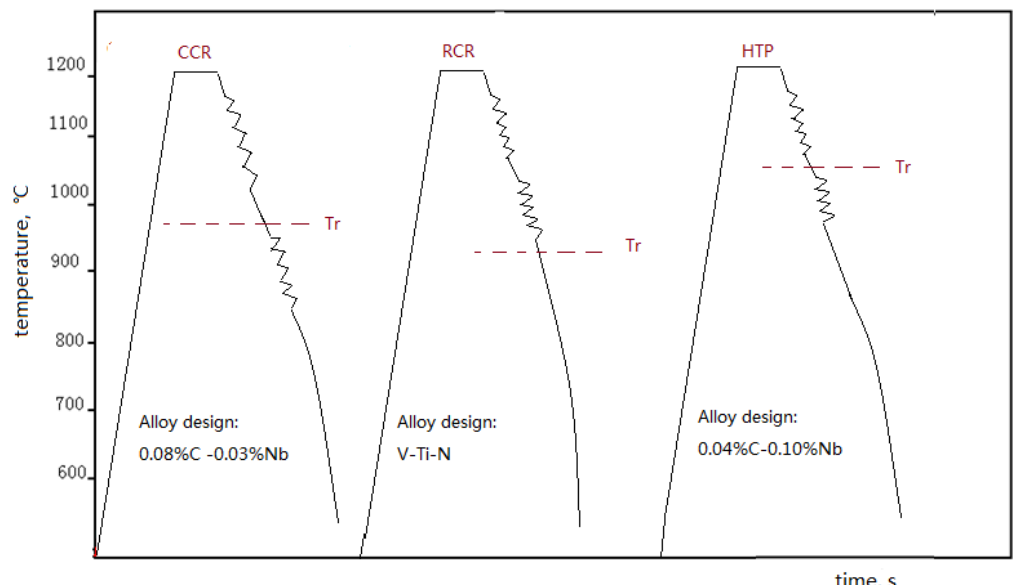

Fig. 1 Schematic illustration of different controlled rolling.

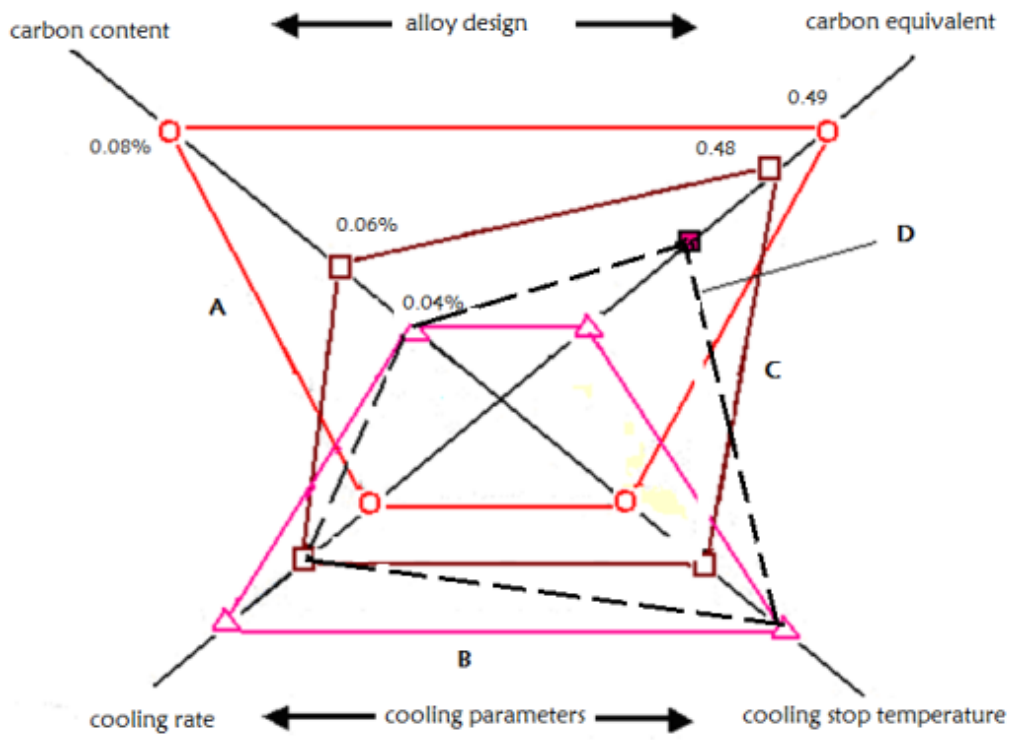

Fig. 2 Metallurgical design of X80 strip.

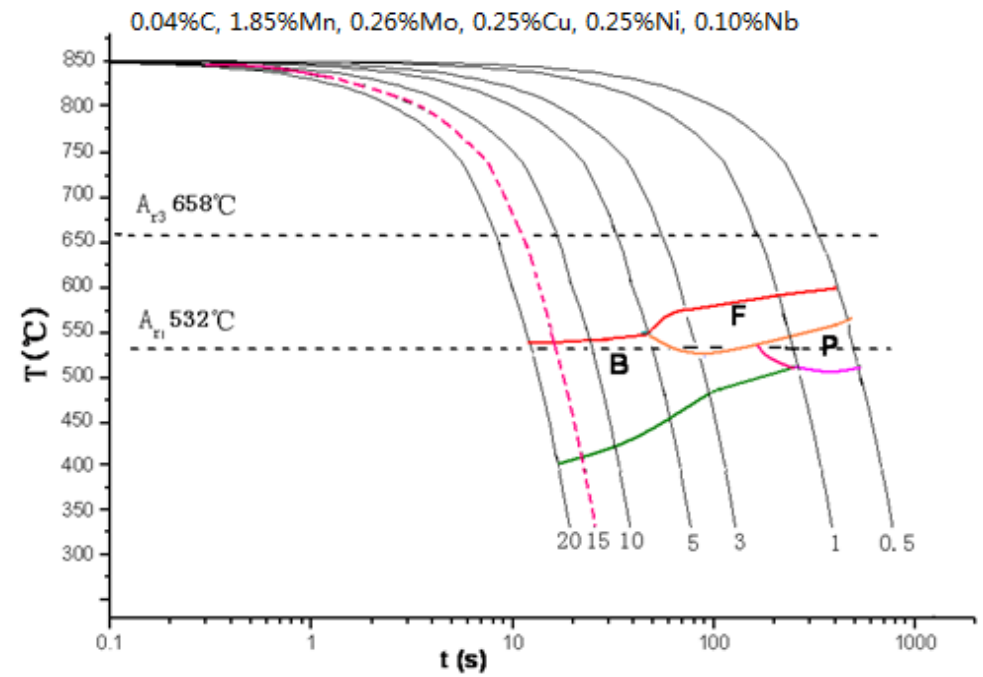

Fig. 3 CCT diagram of X80 strip. 
finishing cooling temperature in the paper "Recent Developments and Applications of TMCP Steel Plates" in 2011 .

\section{Mass Production and Analysis of Mechanical Properties}

Figs. 4 and 5 show the statistical results in $30^{\circ}$ to rolling direction based on above given chemical compositions and production processing. The mean yield strength and ultimate tensile strength are 594 $\mathrm{MPa}$ and $713 \mathrm{MPa}$, respectively. What is more exciting, the test result of DWTT is all $100 \%$, and the average Charpy energy at minus $20^{\circ} \mathrm{C}$ is $342 \mathrm{~J}$.

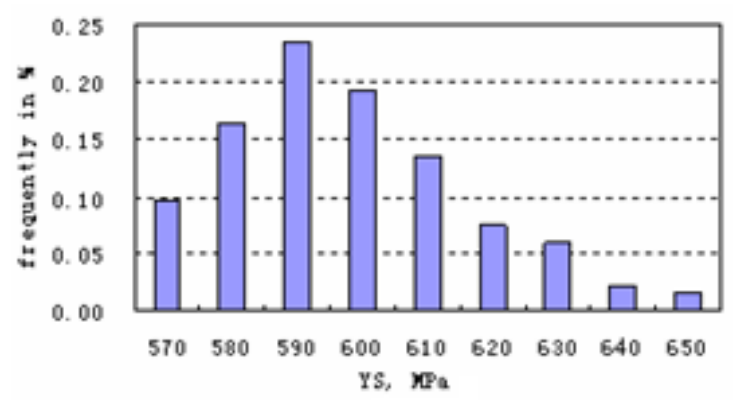

Fig. 6 shows the analysis results of microstructure of X80 strip by metalloscope, SEM and TEM, as shown, the microstructure are composed fine, uniform acicular ferrite, dispersed MA constituents and bainitic lath.

\section{Existing State and Strengthening Effects of Niobium in Different Stage}

In order to confirm the existing state of high $\mathrm{Nb}$ addition and their effects, chemical extraction techniques had been performed to get the precipitated particle of $\mathrm{Nb}(\mathrm{CN})$. The chemical compositions of three test steels are shown in Table 2.

Table 3 shows the analysis results of second phase of

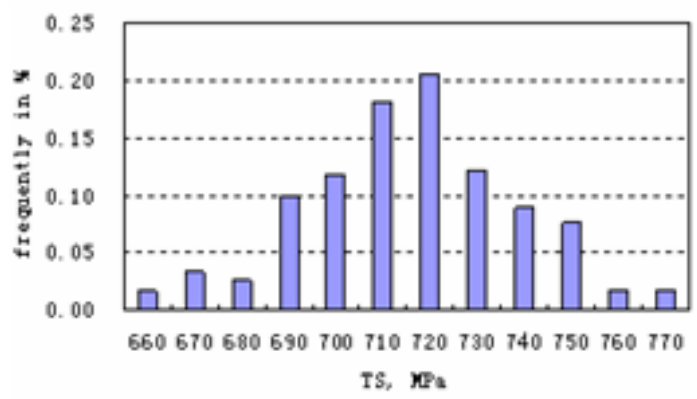

Fig. 4 Test results of tensile test for X80 coil with a thickness of $18.4 \mathrm{~mm}$.

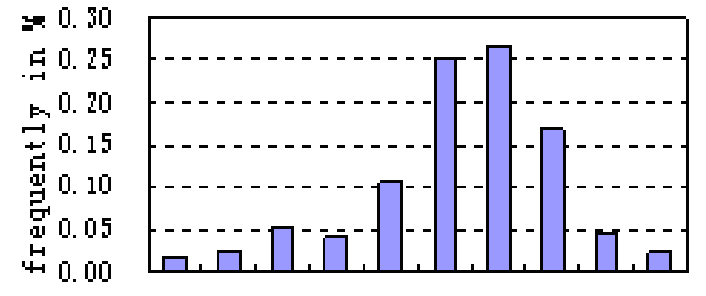

220240260280300320340360380400

$\mathrm{CVN}$ at $-20^{\circ} \mathrm{C}$ in $\mathrm{J}$

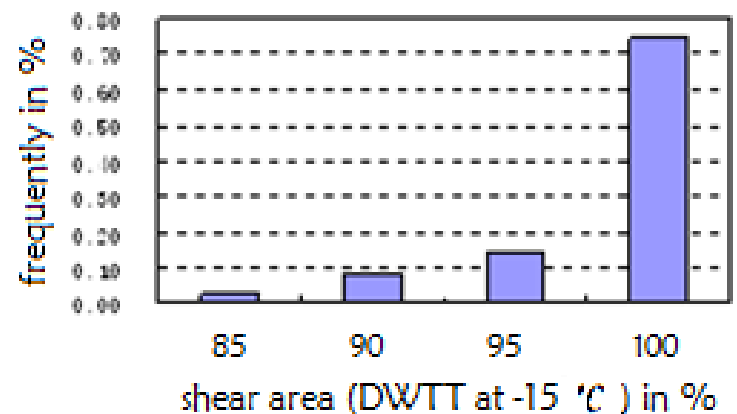

shear area (DWTT at $-15^{\circ} \mathrm{C}$ ) in \%

Fig. 5 Charpy impact energy and DWTT test results, $30^{\circ}$ to the rolling.

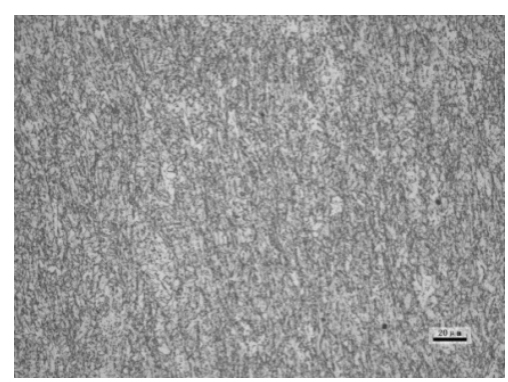

(a) Metalloscope image

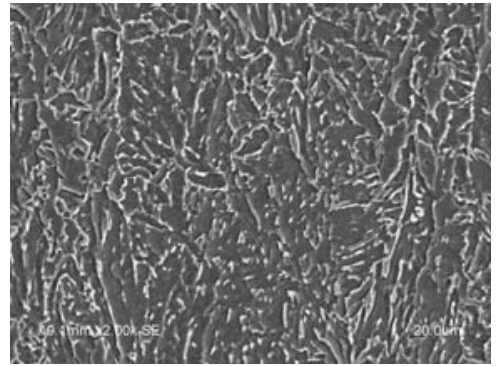

(b) SEM image

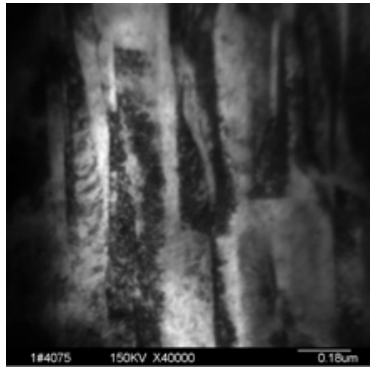

(c) TEM image

Fig. 6 Microstructure of X80 strip. 
Table 2 The chemical composition of test steels.

\begin{tabular}{lllllllll}
\hline No. & state & $\mathrm{C}$ & $\mathrm{N}$ & $\mathrm{Mn}$ & $\mathrm{Mo}$ & $\mathrm{Nb}$ & $\mathrm{Ti}$ & $\mathrm{V}$ \\
\hline 1 & As-rolled & 0.04 & 0.0040 & 1.85 & 0.15 & 0.09 & 0.015 & 0.025 \\
2 & As-rolled & 0.04 & 0.0040 & 1.85 & 0.26 & 0.06 & 0.015 & 0.025 \\
3 & Austeniting & 0.04 & & & & & & \\
4 & As-rolled & 0.04 & 0.0040 & 1.85 & 0.26 & 0.096 & 0.015 & 0.025 \\
5 & Heat treatment & 0.04 & & & & & & \\
\hline
\end{tabular}

Table 3 Existing state of $\mathrm{Nb}$ different stage with different alloy design.

\begin{tabular}{llllllll}
\hline Sampled & \multicolumn{7}{c}{ Mass fraction of each element among the MC、MN、M(C,N)、M2C, wt $/ \%$} \\
\cline { 2 - 8 } No. & $\mathrm{Nb}$ & $\mathrm{Ti}$ & $\mathrm{Mo}$ & $\mathrm{V}$ & $\mathrm{C}^{*}$ & $\mathrm{~N}$ & $\Sigma$ \\
\hline 1 & 0.0391 & 0.0115 & 0.0019 & 0.0004 & 0.0050 & 0.0038 & 0.0617 \\
2 & 0.0229 & 0.0120 & 0.0025 & 0.0003 & 0.0034 & 0.0035 & 0.0446 \\
3 & 0.0099 & 0.0102 & 0.0016 & 0.0002 & 0.0007 & 0.0040 & 0.0266 \\
4 & 0.0483 & 0.0111 & 0.0024 & 0.0003 & 0.0058 & 0.0039 & 0.0698 \\
5 & 0.0875 & 0.0135 & 0.0286 & 0.0052 & 0.0164 & 0.0036 & 0.1548 \\
\hline
\end{tabular}

$\mathrm{MC} 、 \mathrm{MN} 、 \mathrm{M}(\mathrm{C}, \mathrm{N}) 、 \mathrm{M} 2 \mathrm{C}$. As shown from measured results of sample three, $0.0099 \% \mathrm{Nb}$ exists in precipitate of $\mathrm{Nb}(\mathrm{CN})$, namely $0.086 \% \mathrm{Nb}$ is in solution when the slabs are reheated to $1,180{ }^{\circ} \mathrm{C}$. The measured result is consistent with calculated results of Irvine's solubility product equation. The measured results of sample four demonstrated that about half of niobium addition precipitated for as-rolled X80 strip, but there is possible that very fine particle cannot be extracted. The measured results of sample five show that carbide, nitride and carbonitride of $\mathrm{Nb}$ precipitated when sample was reheated to $550^{\circ} \mathrm{C}$, and holding 30 minutes. The measured results of sample one show high Mo contents promote precipitation of $\mathrm{Nb}$ during hot rolling process. For test steel with $0.06 \% \mathrm{Nb}$, only $0.0229 \%$ precipitated during hot rolling process. In addition, as seen from analysis results, almost all nitrogen are fixed by $\mathrm{Ti}, \mathrm{Nb}$ or/and $\mathrm{V}$, and $\mathrm{V}$ contents exist in solution state.

It is clear about retardation recrystallization of high $\mathrm{Nb}$ addition, but the effects of $\mathrm{Nb}$ in solution after rolling need to clarify further, which can be reflected by the relationship between coiling temperature and strength level, as well as aging strain. Fig. 7 gives the analysis results between tensile strength and coiling temperature. As we know, higher coiling temperature is corresponding to high yield strength and low tensile strength, which can be explained solution $\mathrm{Nb}$ still precipitated, but suppressed with decreasing coiling temperature. As coiling temperatures lower, the volume fraction of MA will increase, which is regarded as the reason for high tensile strength at lower coiling temperature. In addition, too lower coiling temperature will lead to aging strain during pipe-making and coating process, which can be balanced by coiling temperature and carbon contents to the interests of steel steels. During this process, $\mathrm{Nb}$ in solution still plays a positive role in improving yield strength.

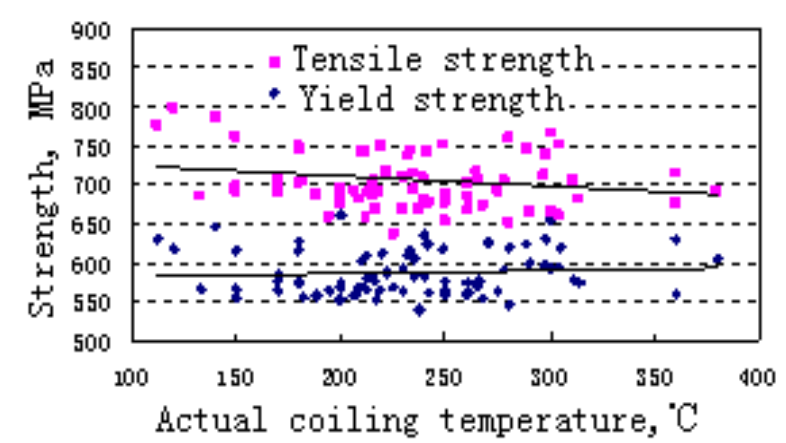

Fig. 7 Effect of coiling temperature on yield and tensile strength.

\section{Latest Application of HTP in Heavy Gauge and Large-Diameter Pipe}

Since successful application of HTP for X80 strip, low carbon and high niobium alloy design coupled with HTP has become the fundamental metallurgical conception for high strength pipeline steels. Together with research institutes, steel mills and pipe makers, 
CITIC-CBMM established three R\&D projects focusing on $\Phi 1,422 \times 21.4 \mathrm{~mm}^{2}$ and $22.0 \mathrm{~mm} \mathrm{X80}$ strip and spiral welded pipe, $\Phi 1,422 \times 25.4 \mathrm{~mm}^{2}, 27.7$ $\mathrm{mm}$ X80 plate and longitudinal welded pipe, as well as recent X90 and weldability research. As validated, HTP manifested its positive to enlarge processing window through higher nonrecrystallized temperature range and flexible adjustment of pass reduction. Up to now, $\Phi 1,422 \times 21.4 \mathrm{~mm}^{2}$ and $22.0 \mathrm{~mm}$ X80 strip and spiral welded pipe had been successfully developed and also passed the assessment and approval by TGRI, the unique institute of CNPC in charge of pipe research. $\Phi 1,422 \times 25.4 \mathrm{~mm}^{2}, 27.7 \mathrm{~mm}$ X80 plate and longitudinal welded pipe had been produced for export order.

\section{Conclusions}

With the contributions of forerunner and predecessor, microalloying has developed to be a complete unity of metallurgy and steel material, and will continue to achieve itself with social need and economic benefits.

\section{References}

[1] Gray, J. M. 2014. “Application of High Strength Linepipe Steels Worldwide: Historical Perspective, Development, Specification and Application." Presented at the 2014 China Oil \& Gas Forum, China.

[2] Korchynsky, M. 1995. "Twenty Years since Microalloying '75." Presented at the Conference Microalloying '95, Pittsburgh, PA.

[3] DeArdo, A. J. 1995. "Modern Thermomechanical Processing of Microalloyed Steel: A Physical Metallurgy Perspective." Presented at the Conference Microalloying '95, Pittsburgh, PA.

[4] Graf, M., Schroder, J., Schwinn, V., and Hulka, K. 2002. "Production of Large Diameter Grade X70 with High Toughness Using Acicular Ferrite Microstructure." Presented at the International Conference on Application and Evaluation of High Grade Linepipes in Hostile Environments, Yokohama, Japan.

[5] Pizzimeni, N., DeVito, A., Bufalini, P., and Pontremoli, M. 1981. "Production and Properties on Pipeline Steels with Non-Polygonal Ferrite Microstructure." Presented at the International Symposium Niobium '81, San Francisco, California.

[6] Webster, S., and Drewett, L. 2010. "The EU Project HIPERC-Performance, Economic Steel Concept for Linepipe and General Structural Use.” Niobium Bearing Structural Steels. 